\title{
Sorption of Arsenic(III) from wastewater using Prosopis spicigera $L$. wood (PsLw) carbon-polyaniline composite
}

\author{
Ramasubbu Dhana Ramalakshmi* \\ Department of Chemistry, Rani Anna Government College for Women, Tirunelveli - 627008 (Tamil \\ Nadu), India; Research centre (St. Xavier's College (Autonomous), Tirunelveli - 627002), Affiliated \\ to Manonmaniam Sundaranar University, Abishekapatti, Tirunelveli-627012 (Tamil Nadu), India \\ Mahalingam Murugan \\ Department of Chemistry, Sri K.G.S. Arts College, Srivaikuntam, Thoothukudi - 628619 \\ (Tamil Nadu), India \\ Vincent Jeyabal \\ Department of Chemistry, St. Xavier's College (Autonomous), Palayamkottai, Tirunelveli \\ - 627002 (Tamil Nadu), India \\ ${ }^{*}$ Corresponding author. Email: dhana.ram11@gmail.com
}

\section{Article Info}

https://doi.org/10.31018/

jans.v13i4.2969

Received: September 5, 2021

Revised: November 3, 2021

Accepted: November 7, 2021

\section{How to Cite}

Ramalakshmi, R. D. et al. (2021). Sorption of Arsenic(III) from wastewater using Prosopis spicigera L. wood (PsLw) carbonpolyaniline composite. Journal of Applied and Natural Science, 13(4), 1283 - 1293. https://doi.org/10.31018/jans.v13i4.2969

\begin{abstract}
Water contamination by toxic heavy metal ions causes a serious public health problem for humans. The present work reports the development of a new adsorbent of PsLw carbon-polyaniline composite by direct oxidation polymerisation of aniline with PsLw carbon for the removal of arsenic (As). The structure and morphologies of the adsorbent were characterised by Fourier transform infrared spectroscopy (FTIR) and Scanning electron microscopy (SEM). The ability of the adsorbent for the removal of $\mathrm{As}$ (III) was estimated by batch and kinetic studies. The optimum adsorption behaviour of the adsorbent was measured at $\mathrm{pH}=6.0$. The equilibrium process was found to be in good agreement with Langmuir adsorption isotherm and the maximum adsorption capacity was $98.8 \mathrm{mg} / \mathrm{g}$ for an initial concentration of $60 \mathrm{mg} / \mathrm{L}$ at $30^{\circ} \mathrm{C}$. The kinetic study followed pseudo-secondorder kinetics. Thermodynamic parameters predict the spontaneous, feasible and exothermic nature of adsorption. Column operation was carried out to remove As(III) bulk and column data obeys the Thomas model. The results indicated that PsLw carbon-polyaniline composite can be employed as an efficient adsorbent than polyaniline for removal of As(III) from wastewater.
\end{abstract}

Keywords: Adsorption, Isotherm, Mass transfer, Polyaniline, PsLw carbon, Thomas model

\section{INTRODUCTION}

Arsenic (As) is released into groundwater and surface water through human activities and natural phenomena. Even though arsenic is essential to human health, its accumulation into the tissues of humans and other organisms through the food chain poses health hazards. A large amount of arsenic ingestion causes adverse effects such as chronic symptoms (dermatitis, pigmentation, myelopathy, peripheral neuropathy, jaundice, renal failure) and acute symptoms (nausea, vomiting, diarrhoea) (Ogata et al., 2006). Arsenic concentrations are found at an elevated level (several thousand times than the potable limit), notably in West Bengal (India), Bangladesh, Taiwan, northern China, Mexico, Chile, Argentina, and parts of the United States of America Japan. World Health Organisation (WHO) lowered the potable limit of arsenic in drinking water from 50 to 10 $\mu \mathrm{g} / \mathrm{L}$ (Mohan and Pittmann, 2007; Fayazi et al., 2016).

Various methods are available to remove arsenic from wastewater, and the adsorption method is more advantageous than others in terms of cost, ease of operation, flexibility, simplicity of design, and insensitivity to toxic pollutants. For adsorptive removal of arsenic adsorbents such as activated carbon, activated alumina, gibbsite, aluminium loaded materials, lanthanum compounds, fly ash, natural solids etc., have been used (Munoz et al., 2002). However, activated carbon plays a major role in any other adsorbents. The adsorption capacity of activated carbon can be enhanced by heteroatoms such as oxygen, hydrogen, nitrogen and phosphorous. They form acidic and basic functional groups and contribute to additional adsorption. This surface modification of the carbon matrix can be affect- 
ed by the impregnation of metals/metal oxides or composite formation with the polymeric material.

Polymer based adsorbents have a wide range of pore structures, strong binding affinities, high adsorption capacity and good mechanical, chemical and thermal stability. Polyaniline is one such polymer that can be used for composite formation with carbon due to easy synthesis, the feasibility of doping, good physicochemical characteristics, mechanical flexibility, environmental stability and easy availability of its monomer. In wastewater treatment, polyaniline is used as an adsorbent due to amine and imine groups that interact with molecules of various contaminants present in polluted water (Li et al., 2015). Pure and modified forms of polyaniline behave as an effective adsorbent for the removal of arsenic and heavy metals (Boeva and Sergeyev, 2014; Jiang et al., 2018; Nodeh et al., 2018; Mahmoud et al., 2018). Polyaniline contains many amine and imine functional groups. It is expected to have interactions with some metal ions, which have the strong affinity to nitrogen atoms in the structure. In the present study, Prosopis spicigera L. wood (PsLw) carbon prepared from cheaply available plant material is impregnated with polyaniline and used for removal of $\mathrm{As}$ (III) from wastewater.

\section{MATERIALS AND METHODS}

\section{Preparation of PsLw carbon-polyaniline composite}

PsLw plant material used in the present work was collected from the dry land area of Palayamkottai in Tirunelveli district, Tamilnadu State, India. The branch and roots of the plant were cut into pieces and piled up on a firing hearth. Before firing, the heaped wood pieces were enclosed by fresh plantain pith and the whole mass was covered and plastered with layers of wet clay. This arrangement prevented the direct entry of air into wood pieces and, hence, prohibited burning wood and becoming ash. After 48 hours of continuous firing and subsequent natural cooling, the activated carbon was obtained. After removing the non-carbonaceous materials, the carbon was isolated, crushed and sieved to 75 micron particles. The composite adsorbent was prepared using the slightly modified literature procedure (Schwarz et al., 1984; Chang et al., 2010). The adsorbent was dried in an air oven at $100{ }^{\circ} \mathrm{C}$ for 8 hours and finally kept in clean air-tight containers. $20 \mathrm{~g}$ of PsLw carbon was mixed with $10 \mathrm{ml}$ of distilled aniline in $1.0 \mathrm{M}$ $\mathrm{H}_{2} \mathrm{SO}_{4}$ and the mixture was cooled in an ice-bath with constant stirring for 2 hours. A pre cooled solution of $0.5 \mathrm{M}$ Ammonium peroxydisulphate in $100 \mathrm{ml}$ of distilled water was added drop by drop under constant stirring for 1 hour. After the addition of APS, the constant stirring was continued for further 3 hours. The reaction mixture was then kept in the refrigerator overnight. The next day it was filtered to recover the product and washed several times with distilled water till the filtrate became colourless. It was washed with acetone and the sample was dried in an air oven at $110{ }^{\circ} \mathrm{C}$ for 5 hours. The dried product was weighed and stored in an airtight container.

\section{Characterisation of adsorbent}

The functional group and surface morphology were analysed by Fourier Transformer Infrared Spectroscopy (JASCO FT/IR - 4700 type A) and Scanning Electron Microscope (Joel, JSM 6390, Oxford Instruments, UK), respectively. The point of zero charge $\left(\mathrm{pH}_{\mathrm{zpc}}\right)$ of PsLw carbon-polyaniline composite was determined by potentiometric titration with acid/alkali (Schwarz et al., 1984). The textural property of the surface area of the adsorbents was studied by the methylene blue method (Palit and Moulik, 2000; Adamson, 1990; Potgiefer, 1991) and Brunauer-Emmett-Teller (BET) nitrogen adsorption method.

\section{Batch adsorption studies}

Batch equilibrium studies were carried out for adsorption of arsenic on PsLw carbon-polyaniline composite. Standard As(III) stock solution of $1000 \mathrm{mg} / \mathrm{L}$ was prepared for batch studies by dissolving $1.32 \mathrm{~g}$ of As(III) oxide with $1000 \mathrm{~mL}$ of deionized water. The effect of $\mathrm{pH}$, initial concentration, contact time, in the presence of other ions and solution temperature of the adsorbate solution on PsLw carbon-polyaniline composite were studied. The sample solutions were analysed at particular time intervals using the literature procedure (Jeffery et al., 1989) for higher concentrations. Samples from the column study were analysed using Atomic Absorption Spectrophotometer (concentration less than $1.0 \mathrm{mg} / \mathrm{L}$ ) (Shimadzu, AA-6300). The lower detectable limit of the spectrophotometric method is $0.25 \mu \mathrm{g} / \mathrm{ml}$. Each sample was analysed twice and the results are reproducible within \pm 1 percent error limit. Further, the results obtained from the spectrophotometric method are comparable with the AAS method (lower detectable limit is $0.01 \mu \mathrm{g} / \mathrm{ml}$ ) and the deviation is \pm 3 percent only, which is within the error limit in order to make use of this process for large scale treatment and small scale for potable water.

The amount of adsorption of As(III) per unit mass of adsorbent $\left(\mathrm{q}_{\mathrm{e}}\right)$ was calculated using Eq. (1)

$$
q_{e}=\left(C_{0}-C_{e}\right) V / W
$$

Where, $C_{o}$ and $C_{e}(\mathrm{mg} / \mathrm{L})$ are the initial and equilibrium concentration of As(III) respectively, $\mathrm{V}$ is the volume of the solution (L) and $W$ is the mass of adsorbent $(\mathrm{g})$.

\section{Adsorption Isotherm Models}

Equilibrium adsorption isotherm expresses the relationship between the surface of the adsorbent and the adsorbate molecule and adsorption efficiency. The linear 
form of Langmuir and Freundlich models were used for isotherm modelling for arsenic sorption on PsLw carbon -polyaniline composite and can be expressed as

$$
\begin{aligned}
& \mathrm{C}_{e} / q_{e}=1 / Q_{0} b+C_{e} / Q_{。} \\
& \log q_{e}=\log K_{f}+1 / n \log C_{e}
\end{aligned}
$$

Where, $C_{e}(\mathrm{mg} / \mathrm{L})$ and $\mathrm{q}_{\mathrm{e}}(\mathrm{mg} / \mathrm{g})$ are the free and sorbed concentration of $\mathrm{As}(\mathrm{III})$ species respectively at equilibrium, $Q_{0}(\mathrm{~L} / \mathrm{mg})$ is the monolayer sorption capacity and b is the Langmuir adsorption equilibrium constant. $\mathrm{K}_{\mathrm{f}}$ $\left(m g^{1-n} g^{-1} L^{n}\right)$ and $1 / n$ are the Freundlich constants related to the adsorption capacity and heterogeneity, respectively.

\section{Adsorption Kinetics}

The kinetics of the adsorption arsenic on PsLw carbonpolyaniline composite are described using pseudo first and second-order models at different concentrations and temperatures. The pseudo first-order rate equation of Lagergren is expressed as

$$
\log \left(q_{e}-q\right)=\log q_{e}-k_{1} t / 2.303
$$

where $\mathrm{q}_{\mathrm{e}}$ and $\mathrm{q}$ are the amounts of As(III) adsorbed at equilibrium and at a time ' $t$ ' and $k_{1}$ is the rate constant for first-order adsorption. The pseudo second-order Ritchie kinetic rate equation can be written as

$$
t / q=\left(1 / k_{2} q_{e}^{2}(\mathrm{cal})\right)+t / q_{e(c a l)}
$$

where $k_{2}$ is the reaction rate constant of second order adsorption and $\mathrm{q}_{\mathrm{e} \text { (cal) }}$ is the numerically determined parameter.

\section{Column Study}

The experimental unit consists of a glass column of 48 $\mathrm{cm}$ height by $3.5 \mathrm{~cm}$ diameter packed with $5 \mathrm{~g}$ of PsLw carbon-polyaniline composite. The column was fitted with cotton screens to separate the adsorbent from the top and bottom stoppers. The arsenic solution was drawn into the column from a height of 1 meter. Elutents were collected at regular interval of time and

Table 1. Physico-chemical characteristics of PsLw carbonpolyaniline composite

\begin{tabular}{ll}
\hline Parameters & Values \\
\hline $\mathrm{pH}$ & 6.5 \\
Moisture Content \% (W/W) & 0.0009 \\
$\begin{array}{l}\text { Surface area }\left(\mathrm{m}^{2} / \mathrm{g}\right)(\text { Nitrogen BET } \\
\text { adsorption method) }\end{array}$ & 245.39 \\
$\begin{array}{l}\text { Surface area }\left(\mathrm{m}^{2} / \mathrm{g}\right) \text { (Methylene } \\
\text { Blue dye adsorption method) }\end{array}$ & 90.21 \\
$\mathrm{pH}_{\mathrm{zpc}}$ & 7.3 \\
Bulk density $(\mathrm{g} / \mathrm{cc})$ & 0.3834 \\
Particle density $(\mathrm{g} / \mathrm{cc})$ & 0.4182 \\
\hline
\end{tabular}

analysed. The data were analysed using Thomas model (Thomas, 1948; Reynolds and Richards, 1996), which is given by the equation.

$$
\log \left(C_{\circ} / C_{e}-1\right)=k q_{。} M / Q-k C_{。} V / Q
$$

where, $\mathrm{C}_{\circ}$ and $\mathrm{C}_{e}$ are the influent and effluent $\mathrm{As}$ (III) concentrations (mg/L) respectively, $k$ is the Thomas rate constant $(\mathrm{mL} / \mathrm{min} / \mathrm{mg}), \mathrm{q}_{\mathrm{o}}$ is the maximum solidphase concentration of solute $(\mathrm{mg} / \mathrm{g}), M$ is the mass of the adsorbent $(\mathrm{g}), Q$ is the influent flow rate $(\mathrm{mL} / \mathrm{min})$ and $V$ is the through put volume $(\mathrm{mL} / \mathrm{min})$.

\section{RESULTS AND DISCUSSION}

\section{Characterisation of adsorbent}

The physio-chemical characteristics of PsLw carbonpolyaniline composite are listed in Table 1.

\section{Fourier Transform Infrared Spectroscopy (FTIR) and Scanning Electron Microscope (SEM) characterisation}

FTIR is used to confirm aniline's polymerization and composite formation with PsLw carbon and As(III) adsorption onto the PsLw carbon. The FTIR spectra of pure PsLw carbon, PsLw carbon-polyaniline composite and As(III) loaded PsLw carbon-polyaniline composite are illustrated in Fig. 1a, 1b and 1c, respectively.

The free PsLw carbon shows three weakly intense peaks at $1613 \mathrm{~cm}^{-1}$ (due to ketone moiety), $1423 \mathrm{~cm}^{-1}$ (O-H in-plane bending) and $961 \mathrm{~cm}^{-1}$ (C-O stretching) (Fig. 1a). Fig. 1b of PsLw carbon-polyaniline composite shows the peak at 3432 and $3266 \mathrm{~cm}^{-1}$ due to the presence of $-\mathrm{N}-\mathrm{H}$ stretching vibration. The peak at 2915 and $2864 \mathrm{~cm}^{-1}$ are due to the presence of $-\mathrm{C}-\mathrm{H}$ stretching in alkanes, while the peak at $1738 \mathrm{~cm}^{-1}$ corresponds to C-N stretching of amino group. The adsorp-

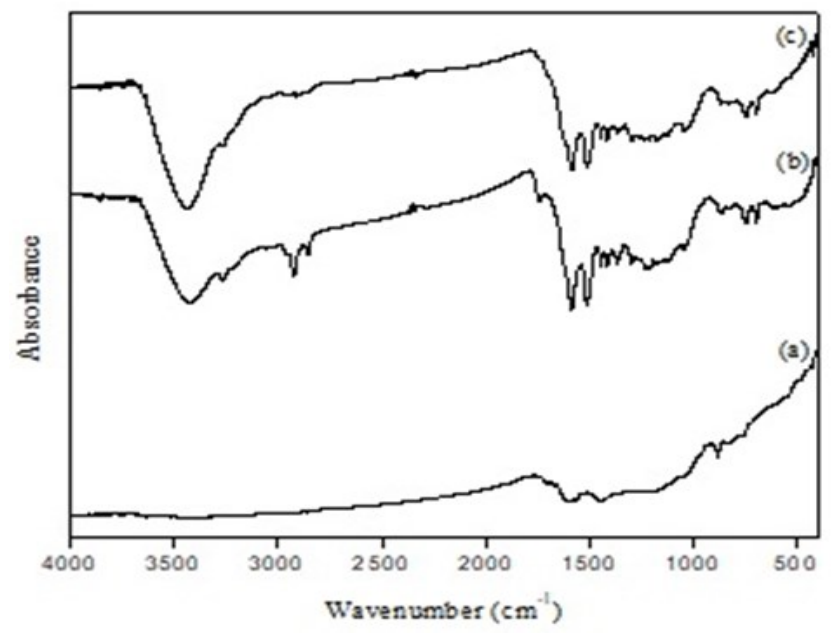

Fig. 1. FTIR spectra of (a) pure PsLw carbon (b) PsLw carbon-polyaniline composite (c) As(III) loaded PsLw carbon-polyaniline composite. 
tion peaks at 1582,1490 and $1211 \mathrm{~cm}^{-1}$ are assigned to the $\mathrm{C}=\mathrm{C}$ stretching mode of the quinoid ring, $\mathrm{C}=\mathrm{C}$ stretching vibration of the benzenoid ring and $\mathrm{C}-\mathrm{N}$ stretching mode, respectively (Yang et al., 2009; Zhou et al., 2015). The weak adsorption band at 1035, 860, 736 and $684 \mathrm{~cm}^{-1}$ exhibits the presence of $\mathrm{C}-\mathrm{O}$ stretching in polymeric structure, $=\mathrm{C}-\mathrm{H}$ bending in alkenes, aromatic $\mathrm{C}-\mathrm{H}$ bending and out plane $\mathrm{O}-\mathrm{H}$ bending, respectively. These stretching frequencies indicate that the modification of PsLw carbon surface with polyaniline is successfully performed.

\section{Effect of pH}

The $\mathrm{pH}$ of the solution is identified as one of the important variables for metal adsorption. The surface of the adsorbent is altered by the solution $\mathrm{pH}$ and changes occur in adsorption process due to the reaction of $\mathrm{H}^{+}$ with the functional groups on the active sites at the surface of the adsorbent. The effect of $\mathrm{pH}$ on the removal of As(III) has been studied by varying the initial $\mathrm{pH}$ of the solution in the range of $\mathrm{pH}=1.0-11.0$ for an initial concentration of $50 \mathrm{mg} / \mathrm{L}$ and $0.5 \mathrm{~g} / \mathrm{L}$ adsorbent dose (Fig. 3).It is evident from Fig. 3 that the amount of As
(III) adsorption increases with rise in $\mathrm{pH}$ and reaches a maximum at $\mathrm{pH}=7.0$ and then decreases. This observation can be correlated with zero point charge of PsLw carbon-ployaniline composite. The zero point charge of PsLw carbon-polyaniline composite is 7.3 and the adsorption of As(III) is controlled by the surface charge of the adsorbent, which mainly depends on the solution pH (Zhu et al., 2009; Purwajanti et al., 2016; Shabnam 2017). Below pH $=7.0 \mathrm{As}(\mathrm{III})$ exists as $\mathrm{H}_{3} \mathrm{AsO}_{3}$ and above $\mathrm{pH}=7.0 \mathrm{As}(\mathrm{III})$ is present as $\mathrm{H}_{2} \mathrm{AsO}_{3}{ }^{-}$and HAs$\mathrm{O}_{3}{ }^{2-}$. But in the polyaniline composite at $\mathrm{pH} \leq 4$, the amine group is protonated and therefore, hydrostatic repulsion could be operative between As(III) species and a protonated amine group. But the adsorption increases with an increase in $\mathrm{pH}$, and therefore complexation between the composite and the As(III) species could not be ruled out (Nodeh et al., 2018). This is evident from the FTIR spectral study and SEM analysis. The FTIR spectra of As(III) loaded PsLw carbonpolyaniline composite is represented in Fig. $1 \mathrm{c}$. The major changes that occur at the vibration modes of 3266,2915 and $2864 \mathrm{~cm}^{-1}$ are diminished and the adsorption bands in the region of $1500-800 \mathrm{~cm}^{-1}$ are weak-
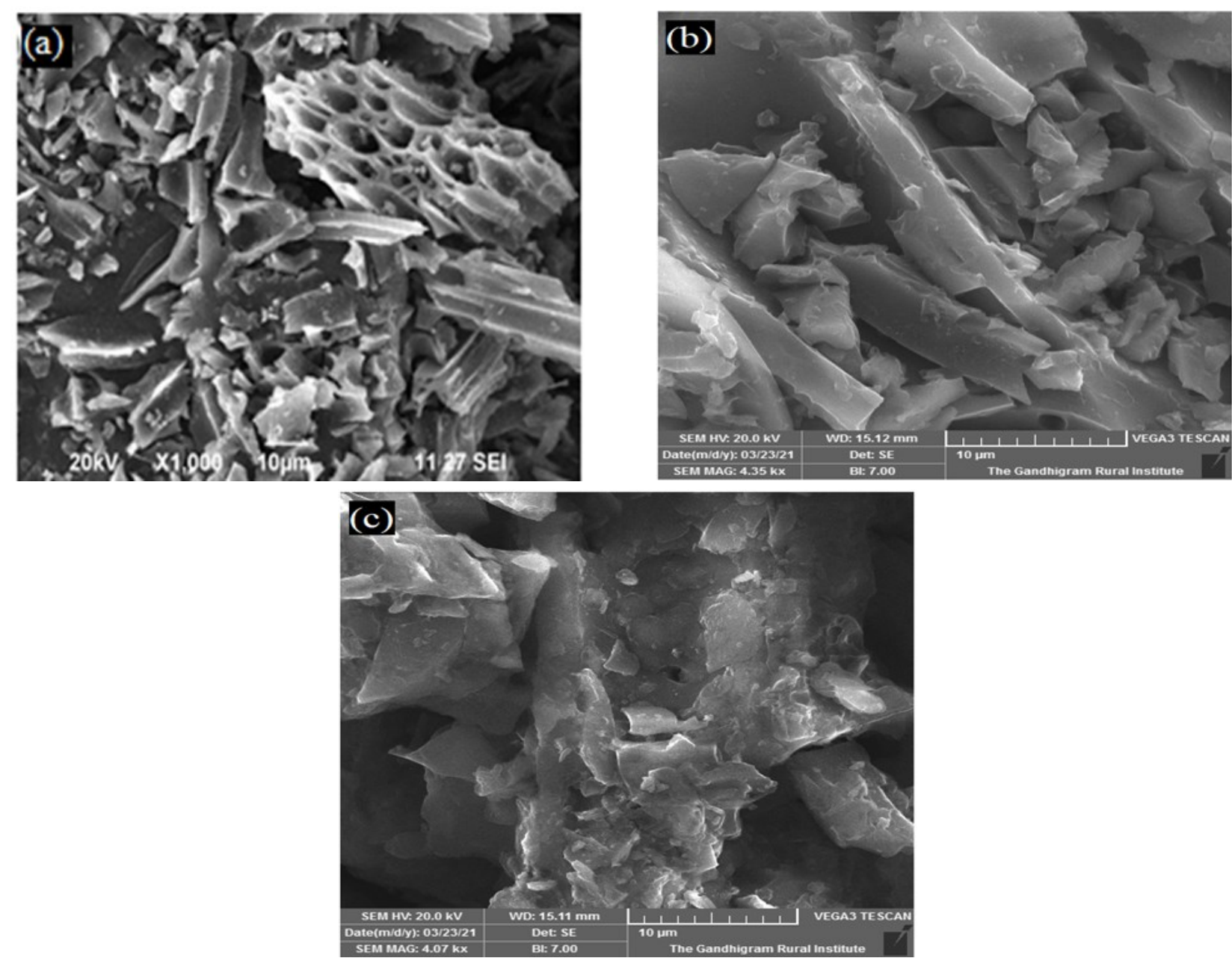

Fig. 2. SEM images of (a) Pure PsLw carbon (b) PSLw carbon-polyaniline composite (c) As(III) loaded PsLw carbonpolyaniline composite. 
ened. These changes confirm the structural modification via complex formation due to As(III) adsorption on PsLw carbon-polyaniline composite. SEM images give information about the surface morphology of the adsorbents. The SEM image of PsLw carbon (Fig. 2 a) exhibits a rough surface with porous and pristine carbon particles. The bright rod-like agglomerated particles are present in the image of PsLw carbon-polyaniline composite and small white patches show the presence of polyaniline on the surface of PsLw carbon (Fig. 2 b). PsLw carbon-polyaniline composite surface is further agglomerated due to the adsorption of As(III) than the free adsorbent shown in Fig. 2 c. These structural changes clearly reveal the adsorption of As(III) on PsLw carbon-polyaniline composite through complex formation.

At $\mathrm{pH}>8.0$, the efficiency decreases due to the repulsion between the anionic species of $\mathrm{As}$ (III) $\left(\mathrm{H}_{2} \mathrm{AsO}_{3}{ }^{-} /\right.$ $\mathrm{HAsO}_{3}{ }^{2-}$ ) and the negatively charged surface of the adsorbent. Thus the solution $\mathrm{pH}$ controls the sorption process and the batch studies are carried at the neutral $\mathrm{pH}=6.0$ for applying the process to household applications.

\section{Effect of contact time and initial concentration}

The effect of contact time and initial concentration on

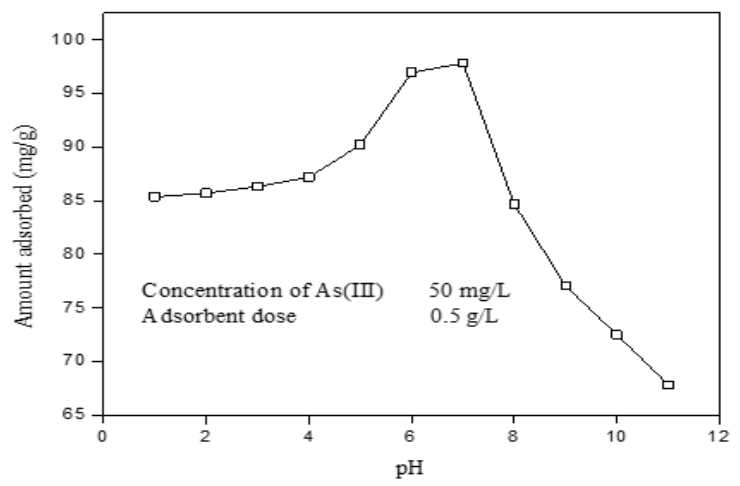

Fig. 3. Effect of $p H$ on the adsorption of As(III) by PsLw carbon-polyaniline composite

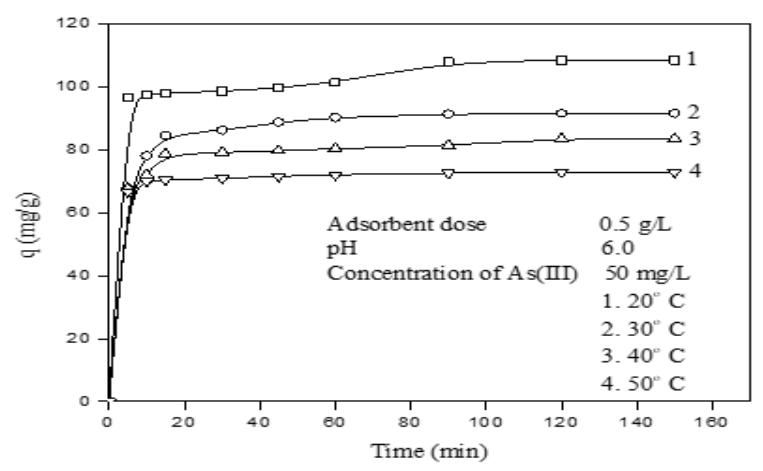

Fig. 5. Effect of temperature on the removal of As(III) by PsLw carbon-polyaniline composite
As(III) sorption on PsLw carbon-polyaniline composite is depicted in Fig. 4. The As(III) removal capacity increases with contact time and initial concentration and equilibrium are attained within $60 \mathrm{~min}$. The maximum As(III) uptake capacities of PsLW carbon-polyaniline composite are $80.8,91.5$ and $98.8 \mathrm{mg} / \mathrm{g}$ for initial concentrations 40,50 and $60 \mathrm{mg} / \mathrm{L}$ at $150 \mathrm{~min}$, respectively. After equilibrium, the adsorption efficiency is almost constant because the active sites of the adsorbent are saturated with As(III) species.

\section{Effect of temperature}

The As(III) removal efficiency of PsLw carbonpolyaniline composite is studied under different temperatures ranging from $20-50{ }^{\circ} \mathrm{C}$ and is shown in Fig. 5 . The maximum adsorption capacity obtained at 20, 30, 40 and $50^{\circ} \mathrm{C}$ are $108.4,91.5,83.5$ and $72.8 \mathrm{mg} / \mathrm{L}$ respectively for an initial concentration of $50 \mathrm{mg} / \mathrm{L}$ and adsorbent dosage $0.5 \mathrm{~g} / \mathrm{L}$. The maximum removal was noted at $20^{\circ} \mathrm{C}$ and a further increase in temperature resulted in a decrease in removal efficiency. This indicated that the sorption process is exothermic in nature and the increase in temperature is unfavourable for As (III) adsorption. This decrease in adsorption with increased temperature may be due to the weakening of adsorptive forces between the active sites of the PsLw

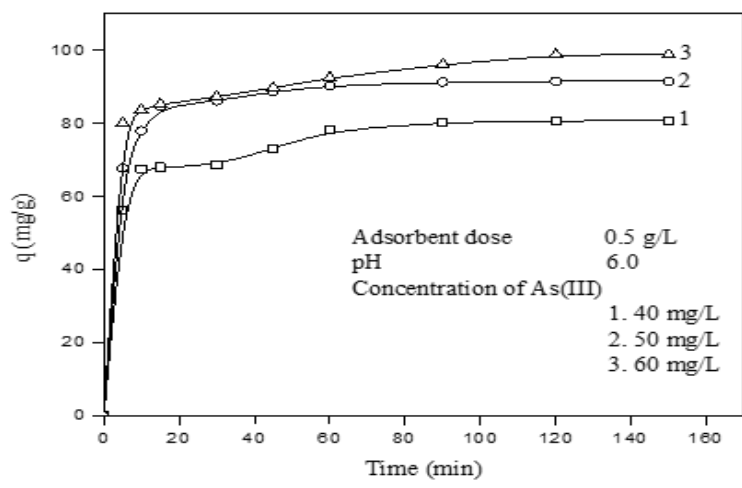

Fig. 4. Effect of contact time and initial concentration on the removal of As(III) by PsLw carbon-polyaniline composite

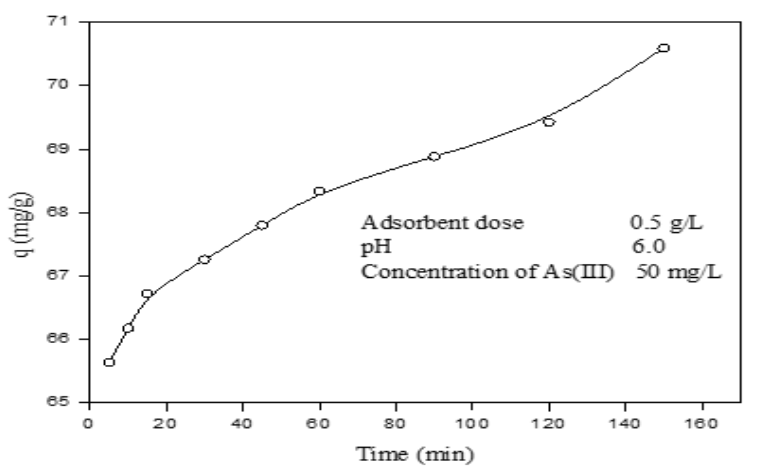

Fig. 6. Effect of As(III) removal by PsLw of carbonpolyaniline composite in the presence of $\mathrm{NO}_{3}{ }^{-}, \mathrm{Cl}, \mathrm{SO}_{4}{ }^{2-}$ and $\mathrm{CO}_{3}{ }^{2-}$ ions 
carbon-polyaniline composite and As(III) species and between the adjacent molecules of the adsorbed phase (Lashkenari et al., 2011).

\section{Effect of coexisting anions}

The effect of coexisting anions such as carbonate, chloride, nitrate and sulphate of concentration $0.001 \mathrm{M}$ each on the adsorption of As(III) was examined and are presented in Fig. 6. The sorption of As(III) increases with contact time and equilibrium was attained at 90 $\mathrm{min}$. The amount of As(III) sorbed is found to be 70.5 $\mathrm{mg} / \mathrm{g}$ for an initial concentration of $50 \mathrm{mg} / \mathrm{L} \mathrm{As}(\mathrm{III})$ and adsorbent dosage $0.5 \mathrm{~g} / \mathrm{L}$. This is lower than the adsorption of $A s(I I I)$ in the absence of these ions. This may be due to the competitive interaction of As(III) on the same site of the adsorbent surface with the above ions. (Bhaumik et al., 2015)

\section{Adsorption isotherms}

Adsorption isotherms are used to describe the distribution of molecules between the liquid and solid phase at adsorption equilibrium. Langmuir and Freundlich adsorption isotherms are classical models used to evaluate the equilibrium between metal ion adsorbed onto adsorbent and the metal ion in solution. The experimental data obtained under various concentrations and temperatures were fitted with a linearised form of Langmuir and Freundlich isotherms represented by equations (2) and (3), respectively. The Langmuir isotherm plots at different initial concentrations and temperatures are shown in Fig. 7. The maximum adsorption capacity $\mathrm{Q}_{\mathrm{o}}(\mathrm{mg} / \mathrm{g})$ and the Langmuir adsorption constant b $(\mathrm{L} /$ $\mathrm{mg}$ ) were calculated from the slope and intercept of the linear plot $\mathrm{C}_{\mathrm{e}} / \mathrm{q}$ vs $\mathrm{C}_{\mathrm{e}}$, respectively. Freundlich constants related to adsorption capacity $\left(\mathrm{K}_{\mathrm{f}}\right)$ and heterogeneity $(1 / n)$ are calculated from the slope and intercept of the linear plot between $\log q_{e}$ and $\log C_{e}$, respectively (Figures not shown). Table 2 exhibits the isotherm constants for both isotherms and correlation coefficients of Langmuir and Freundlich isotherms. The correlation coefficients $\left(R^{2}\right)$ showed the sorption process best fit to Langmuir isotherm than Freundlich and it confirms that the chemical forces govern the adsorption process. The maximum adsorption efficiency of PsLw carbonpolyaniline composite is found to be $88.18 \mathrm{mg} / \mathrm{g}$ for an initial concentration of $50 \mathrm{mg} / \mathrm{L}$ and at $20^{\circ} \mathrm{C}$. Further, it is observed that the Freundlich adsorption isotherm parameter $\mathrm{n}$ is negative; $\mathrm{K}_{\mathrm{f}}$ value deviates from the experimental values, which makes the Freundlich isotherm model unsuitable for the given system. But the adsorption isotherm fits well the Langmuir isotherm model, which shows a monolayer coverage of As(III) onto PsLw carbon-polyaniline composite.

Weber and Chakraborti (1974) expressed the feasibility of the sorption process in terms of a dimensionless constant known as separation factor $\left(R_{L}\right)$ given by

\section{equation 7 .}

$$
R_{L}=1 /\left(1+b C_{\circ}\right)
$$

The $R_{L}$ values of the sorption process at different concentrations and temperatures are exhibited in Table 2 and the values fall in the range of $0 \leq R_{L}<1$, which implies that the sorption process is favourable under the studied conditions (Mckay et al., 1982).

\section{Adsorption kinetics}

The kinetics of the removal study is important to evaluate adsorption dynamics. The rate of adsorption of As (III) onto PsLw carbon-polyaniline composite was investigated using Lagergren's (1898) pseudo first order and Ho and McKay (1999) pseudo second-order models, which are represented by equations 4 and 5 , respectively. The linear plot of $t / q_{t} v s t$ for the pseudo second-order model at different concentrations and temperatures is given in Fig. 8 (For the first order the plots are not given). The parameters obtained for the pseudo first and pseudo second-order kinetics are exhibited in Table 3. The experimental data showed a good agreement with the pseudo-second order. The regression coefficient value $\left(R^{2}\right)$ for pseudo second order was higher than the pseudo first order model at different concentrations and temperatures. The $q_{e}(\mathrm{cal})$ values of pseudo second-order are close to the $q_{e}$ (exp) than the $\mathrm{q}_{\mathrm{e}}$ (cal) of pseudo first-order model. These results confirm that the removal of As(III) using PsLw carbonpolyaniline composite is better described and controlled by pseudo second-order kinetics (Lashkenari et al., 2011).

\section{Thermodynamic parameters}

The mechanism and nature of the adsorption process are determined with the thermodynamic parameters such as free energy change $\left(\Delta G^{\circ}\right)$, enthalpy change $\left(\Delta \mathrm{H}^{\circ}\right)$ and entropy change $\left(\Delta \mathrm{S}^{\circ}\right)$. The relationship between the equilibrium constant $\mathrm{K}_{\mathrm{o}}$ and free energy change $\left(\Delta G^{\circ}\right)$ of the adsorption process is given by equation (8). The enthalpy change $\left(\Delta \mathrm{H}^{\circ}\right)$ and entropy change $\left(\Delta S^{\circ}\right)$ can be obtained from the equations (9) and (10).

$$
\begin{aligned}
& \Delta G^{\circ}=-R T \ln K_{o} \\
& \ln K=\left(\Delta S^{\circ} / R\right)-\left(\Delta H^{\circ} / R T\right) \\
& \Delta G^{\circ}=\Delta H^{\circ}-T \Delta S^{\circ}
\end{aligned}
$$

where $R$ is the universal gas constant $(8.314 \mathrm{~J} / \mathrm{mol} \mathrm{K})$ and $T$ is the absolute temperature $(K)$. Using Khan and Singh method, the equilibrium constant $\mathrm{K}_{\mathrm{o}}$ is calculated 
Ramalakshmi, R. D. et al. / J. Appl. \& Nat. Sci. 13(4), 1283 - 1293 (2021)

Table 2. Langmuir and Freundlich constants at different concentrations and temperatures

\begin{tabular}{lllllllll}
\hline & \multicolumn{3}{c}{ Langmuir Isotherm } & \multicolumn{3}{c}{ Freundlich Isotherm } \\
\hline $\mathbf{C}_{\mathbf{o}}(\mathbf{m g} / \mathbf{L})$ & $\mathbf{T e m p}\left({ }^{\circ} \mathbf{C}\right)$ & $\mathbf{Q}_{\mathbf{o}}(\mathbf{m g} / \mathbf{g})$ & $\mathbf{b}(\mathbf{L} / \mathbf{m g})$ & $\mathbf{R}_{\mathbf{L}}$ & $\mathbf{R}^{2}$ & $\mathbf{n}$ & $\mathbf{K}_{\mathbf{f}}$ & $\mathbf{R}^{\mathbf{2}}$ \\
\hline 40 & 30 & 55.16 & 1.32 & 0.0185 & 0.9880 & -7.0116 & 94.1217 & 0.7456 \\
50 & 30 & 68.49 & 0.42 & 0.0453 & 0.9958 & -5.2348 & 143.6250 & 0.9509 \\
60 & 30 & 77.88 & 0.29 & 0.0541 & 0.9964 & -2.1793 & 255.1937 & 0.8881 \\
50 & 20 & 88.18 & 0.90 & 0.0217 & 0.9984 & -6.2861 & 162.1586 & 0.9947 \\
50 & 30 & 68.49 & 0.42 & 0.0453 & 0.9958 & -5.2348 & 143.6250 & 0.9509 \\
50 & 40 & 59.40 & 0.33 & 0.0571 & 0.9952 & -3.2347 & 117.0760 & 0.9772 \\
50 & 50 & 52.61 & 0.25 & 0.0737 & 0.9994 & -2.1193 & 113.5952 & 0.9627 \\
\hline
\end{tabular}

Table 3. Comparison of pseudo-first order and pseudo-second order kinetic parameters

\begin{tabular}{llllccccc}
\hline & & & \multicolumn{3}{c}{ Pseudo first Order } & \multicolumn{3}{c}{ Pseudo second Order } \\
\cline { 4 - 9 } $\begin{array}{c}\mathbf{C}_{\mathbf{o}} \\
(\mathbf{m g} / \mathbf{L})\end{array}$ & $\begin{array}{l}\text { Temp } \\
\left({ }^{\circ} \mathbf{C}\right)\end{array}$ & $\begin{array}{c}\mathbf{q}_{\mathbf{e}}(\mathbf{e x p}) \\
(\mathbf{m g} / \mathbf{g})\end{array}$ & $\begin{array}{c}\mathbf{k}_{\mathbf{1}} \\
\left(\mathbf{m i n}^{-1}\right)\end{array}$ & $\begin{array}{c}\mathbf{q}_{\mathbf{e}}(\mathbf{c a l}) \\
(\mathbf{m g} / \mathbf{g})\end{array}$ & $\mathbf{R}^{2}$ & $\begin{array}{c}\mathbf{k}_{2} \\
(\mathbf{g} / \mathbf{m g} / \mathbf{m i n})\end{array}$ & $\begin{array}{c}\mathbf{q}_{\mathbf{e}}(\mathbf{c a l}) \\
(\mathbf{m g} / \mathbf{g})\end{array}$ & $\mathbf{R}^{2}$ \\
\hline 40 & 30 & 80.83 & 0.0342 & 30.61 & 0.7999 & 0.0038 & 83.80 & 0.9958 \\
50 & 30 & 91.52 & 0.0202 & 17.88 & 0.6865 & 0.0073 & 92.03 & 0.9997 \\
60 & 30 & 98.8 & 0.0190 & 15.21 & 0.8192 & 0.0085 & 99.94 & 0.9991 \\
50 & 20 & 108.41 & 0.0259 & 05.40 & 0.6631 & 0.0144 & 109.77 & 0.9999 \\
50 & 30 & 91.52 & 0.0202 & 17.88 & 0.6865 & 0.0073 & 92.03 & 0.9997 \\
50 & 40 & 83.52 & 0.0198 & 19.56 & 0.9588 & 0.0035 & 84.01 & 0.9999 \\
50 & 50 & 72.88 & 0.0182 & 21.11 & 0.9801 & 0.0032 & 73.21 & 0.9991 \\
\hline
\end{tabular}

by plotting In $\left(q_{e} / C_{e}\right)$ versus $q_{e}$ and extrapolating $q_{e}$ to zero under different temperatures (Figures not shown). The slope and intercept values of the plot of $\operatorname{lnK}_{0}$ against $1 / \mathrm{T}$ give enthalpy change $\left(\Delta \mathrm{H}^{\circ}\right)$ and entropy change $\left(\Delta S^{\circ}\right)$, respectively.

The thermodynamic parameters are listed in Table 4. The negative $\Delta \mathrm{G}^{\circ}$ values at different temperatures confirmed the spontaneous nature of the adsorption process. The negative $\Delta \mathrm{H}^{\circ}$ values indicate that $\mathrm{As}$ (III) adsorption on PsLw carbon-polyanilne composite is exothermic. The positive $\Delta S^{\circ}$ value indicates the degrees of freedom increased at the solid-liquid interface during the adsorption of As(III) on the adsorbent. Thus the adsorption of As(III) on PsLw carbon-polyaniline composite is spontaneous, feasible and exothermic in nature (Zhou et al., 2015).

\section{Pore diffusion and Mass transfer}

In the batch sorption process, the intraparticle diffusion is the rate-controlling step and the uptake of adsorbate varies with time which are analysed by Finkiam diffusion law. The intra-particle diffusion is given as

$$
q=k_{i} t^{1 / 2}+c
$$

Eq.11

Where, $k_{i}$ is the intra-particle diffusion rate constant and c gives the thickness of the boundary layer. In the ad- sorption process, adsorbate molecules moved from the bulk of the solution into solid adsorbent surface through an intra-particle diffusion process and it is the ratelimiting step (Semerjian, 2010). The multi-linear nature of intra-particle diffusion model is obtained by the plot of amount of adsorbed $(\mathrm{mg} / \mathrm{g})$ against $\mathrm{t}^{1 / 2}\left(\mathrm{~min}^{1 / 2}\right)$, which is shown in Fig. 9 (a). The plot is linear for some initial contact time and do not pass through the origin. The slope of the initial linear portion characterises the rate of intra-particle diffusion (Table 4). This indicates that the adsorbate molecules get adsorbed in the first step and slowly entered into the pores of PsLw carbonpolyaniline composite in the second step (Podder and Majumder, 2016).

The extent of transfer of adsorbate molecules from the bulk solution to the solid adsorbent surface is governed by intra-particle diffusion and the intra-particle diffusion is verified by mass transfer equation. McKay proposed the mathematical model of mass transfer, which is used for the study of the present system and is given by

$$
\ln \left(C_{t} / C_{o}-1 / 1+m k\right)=\left[(1+m k / m k) \beta_{L} S_{s}\right] t+(m k / 1+m k)
$$

Eq. 12

Where $C_{o}(\mathrm{mg} / \mathrm{L})$ is the initial adsorbate concentration and $C_{t}(\mathrm{mg} / \mathrm{L})$ is the adsorbate concentration after time $t$, ' $m$ ' is the mass of adsorbent per unit volume of parti- 
Table 4. Thermodynamic parameters, pore diffusion and mass transfer coefficients

\begin{tabular}{ccccccc}
\hline $\begin{array}{c}\mathbf{T} \\
(\mathrm{K})\end{array}$ & $\mathbf{C}_{\mathbf{0}}(\mathbf{m g} / \mathbf{L})$ & $\begin{array}{c}-\Delta \mathbf{G}^{\circ} \\
(\mathbf{K J} / \mathbf{m o l})\end{array}$ & $\begin{array}{c}-\Delta \mathbf{H}^{\circ} \\
(\mathbf{K J} / \mathbf{m o l})\end{array}$ & $\begin{array}{c}\Delta \mathbf{S}^{\circ} \\
(\mathrm{J} / \mathbf{m o l ~ K})\end{array}$ & $\begin{array}{c}\left(\mathbf{k}_{\mathbf{i}}\right) \\
\left(\mathbf{m g} / \mathbf{g} / \mathbf{m i n}^{1 / 2}\right)\end{array}$ & $\boldsymbol{\beta}_{\mathbf{L}} \times \mathbf{1 0}^{-4}$ \\
\hline 303 & 40 & - & - & - & 3.2494 & - \\
303 & 50 & - & - & - & 6.3335 & - \\
303 & 60 & - & - & - & 7.5368 & - \\
293 & 50 & 63.12 & 47.81 & 0.54 & 5.3568 & 0.3626 \\
303 & 50 & 64.11 & - & - & 6.3335 & 0.5094 \\
313 & 50 & 64.61 & - & - & 6.9214 & 0.5473 \\
323 & 50 & 64.98 & - & - & 7.1028 & 0.6558 \\
\hline
\end{tabular}
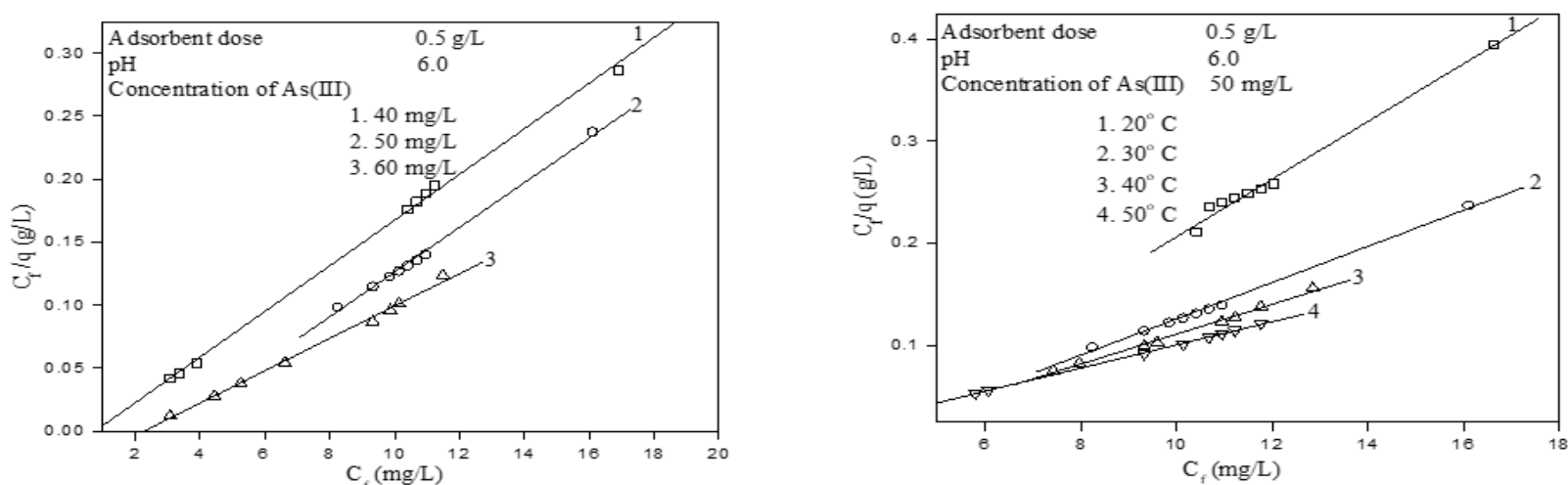

Fig. 7. Langmuir isotherm for As(III) adsorption onto PsLw carbon-polyaniline composite at different concentrations and temperatures.
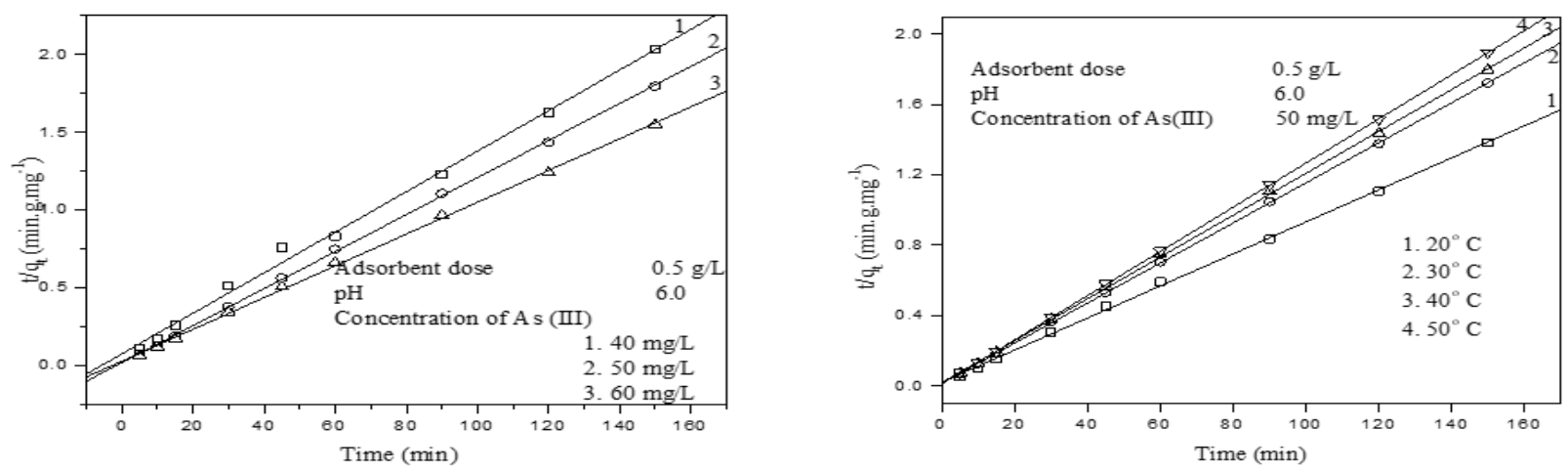

Fig. 8. Pseudo-second order plot of As(III) onto PsLw carbon-polyaniline composite at different concentrations and temperatures.

cle free solution $(\mathrm{g} / \mathrm{L}), \mathrm{k}(\mathrm{L} / \mathrm{g})$ is the product of Langmuir constants $Q_{o}$ and $b, \beta_{L}(\mathrm{~cm} / \mathrm{s})$ is the mass transfer coefficient while $S_{S}$ is the outer surface area of adsorbent per unit volume of particle free slurry $\left(\mathrm{cm}^{-1}\right)$. The values of ' $m$ ' and ' $S_{s}$ ' were calculated using the relations (13) and (14),

$$
\begin{aligned}
m & =W / v \\
\mathrm{~S}_{\mathrm{s}} & =6 \mathrm{~m} /\left(1-\varepsilon_{\mathrm{p}}\right) \mathrm{d}_{\mathrm{p}} \rho_{\mathrm{p}}
\end{aligned}
$$

Where $W$ is the weight of adsorbent (g), ' $v$ 'is the volume of particle free adsorbate solution $(L), d_{p}$ is the particle diameter $(\mathrm{cm}), \rho_{p}$ is the density of adsorbent $\left(\mathrm{g} / \mathrm{cm}^{3}\right)$ and $\varepsilon_{\mathrm{p}}$ is the porosity of adsorbent particle. The plot of $\ln \left[\left(C_{t} / C_{0}\right)-(1 / 1+m k)\right]$ against $t$ is a straight line and is shown in Fig. 9 (b). From the slope and intercept of the plot, the mass transfer coefficient $\beta_{\mathrm{L}}$ was calculated and is given in Table 4 . The linear behaviour of the plot exhibits the fast movement of As(III) from the bulk solution to the solid adsorbent surface. 


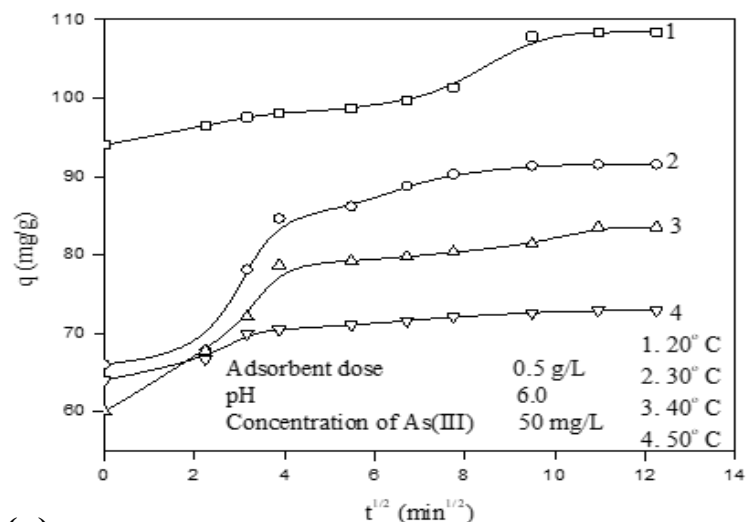

(a)

Fig. 9. Plots of As(III) adsorption of (a) intraparticle diffusion (b) mass transfer onto PsLw carbon-polyaniline composite at different temperatures.

The mass transfer coefficient increases with an increase in temperature. This shows that mass transfer is also a part of the sorption process.

\section{Column study}

Column study can be used to apply the adsorption of As(III) on PsLw carbon-polyaniline composite for large scale treatment. The Thomas kinetic model (Thomas, 1948 ) is one of the most widely used methods to study fixed bed columns. The maximum solid phase concentration of the solute on an adsorbent and the adsorption rate constant for continuous adsorption process in column studies is determined from equation 6 (Roy et al., 2013). In column operation, the breakthrough curve for As(III) adsorption at optimum $\mathrm{pH}=6.0$ onto PsLw carbon-polyaniline composite with flow rate $(3 \mathrm{~mL} / \mathrm{min})$ is displayed in Fig. 10. The effluent concentration of As (III) was found to be zero for the first 169 bed volumes.

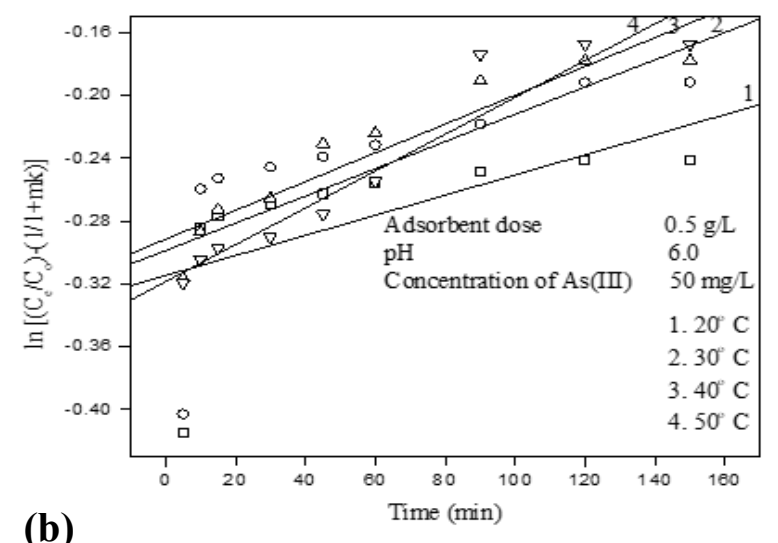

(b)
After 169 bed volumes, the retention concentration of As(III) slowly decreased with the increase of bed volumes. Thomas rate constant $(\mathrm{K}=1.026 \mathrm{~mL} / \mathrm{min} / \mathrm{mg})$ and maximum solid phase concentration $\left(q_{0}=0.9069 \mathrm{mg} / \mathrm{g}\right)$ was determined from the slope and intercept of the plot $\log \left(C_{0} / C_{e}-1\right)$ versus $V$. When the column was saturated with $\mathrm{As}(\mathrm{III})$, it was eluted with $0.1 \mathrm{M} \mathrm{NaOH}$. The column study is thus useful for the practical applicability of PsLw carbon-polyaniline composite in removing As(III).

\section{Desorption studies}

Desorption is one of the important factors in adsorbent marketing that can influence the cost of the removal process. The $\mathrm{pH}$ of the adsorbate plays an important role in the adsorption of $\mathrm{As}$ (III) on PsLw carbonpolyaniline composite. The uptake of As(III) decreases with increasing $\mathrm{pH}$ and therefore, desorption is carried out using $0.1 \mathrm{M} \mathrm{NaOH}$. As(III), desorption is $93 \%, 89 \%$,

Table 5. Adsorption efficiency of other adsorbents

\begin{tabular}{|c|c|c|}
\hline Adsorbents & $\begin{array}{l}\text { Adsorption } \\
\text { capacity }(\mathrm{mg} / \mathrm{g})\end{array}$ & References \\
\hline Hollow Polyaniline Microsphere/ $\mathrm{Fe}_{3} \mathrm{O}_{4}$ nano composite & 28.27 & Dutta et al., 2020 \\
\hline Magnetic polyaniline-doped strontium-titanium nanocomposite & 67.11 & Nodeh et al., 2018 \\
\hline Polyaniline/NickelFerrite-polyaniline composite & $25.2 / 25$ & Agrawal \& Singh 2016 \\
\hline Polyaniline $/ \mathrm{Fe}^{\circ}$ & 232.5 & Bhaumik et al., 2015 \\
\hline $\mathrm{Fe}_{3} \mathrm{O}_{4} @$ Polyaniline & 1.066 & Zhou et al., 2015 \\
\hline PsLw carbon & 65.41 & JansiRani et al., 2014 \\
\hline Polyaniline/polystyrene & 52 & Davodi \& Jahangiri 2014 \\
\hline Polyaniline/rice husk nano composite & 34.48 & Lashkenari et al., 2011 \\
\hline Polyaniline/Sawdust & 2.08 & Ansari et al., 2008 \\
\hline PsLw carbon-polyaniline composite & 98.8 & Present study \\
\hline
\end{tabular}




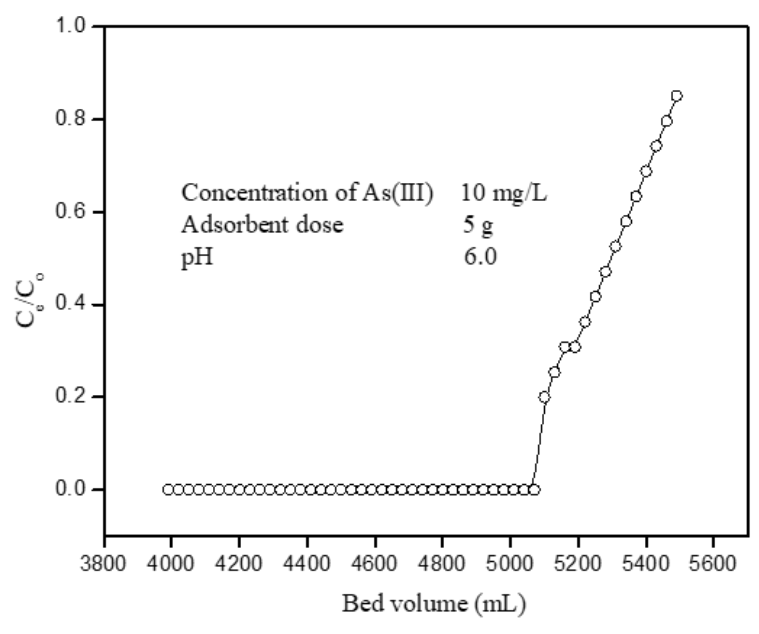

Fig. 10. Breakthrough curve for adsorption of As(III) on PsLw carbon-polyaniline composite

and $86 \%$ for first, second and third cycles, respectively.

\section{Comparison with other adsorbents}

The adsorption efficiency varies with the nature and characteristics of adsorbent, adsorbate $\mathrm{pH}$, dosage of adsorbent, temperature and initial concentration of adsorbate solution. The As(III) adsorption capacity of PsLw carbon-polyaniline composite compared with other adsorbents is given in Table 5. PsLw carbonpolyaniline composite has comparable adsorption capacity with other adsorbents.

\section{Conclusion}

PsLw carbon-polyaniline composite was prepared by direct oxidative polymerisation of aniline mixed with PsLw carbon. The removal of As(III) from aqueous solution at different initial concentration and temperature in a batch sorption mode was carried out at $\mathrm{pH}=6.0$. The adsorption capacity decreased with increase in $\mathrm{pH}$ and temperature. Adsorption of As(III) followed pseudosecond order kinetics and Langmuir isotherm was suitable for describing the adsorption of As(III) onto PsLw carbon-polyaniline composite. Thermodynamic parameters indicated that As(III) adsorption on PsLw carbonpolyaniline composite was spontaneous, feasible, and exothermic in nature. The sorption of As(III) took place through complex formation, inter-particle diffusion and mass transfer. Column study provided the applicability of this process to a large/industrial scale. Modified polyaniline with PsLw carbon showed an improved ability to adsorb As(III) from wastewater than the pristine polyaniline. PsLw carbon-polyaniline composite is a simple, easily available low-cost adsorbent and it could be used for the treatment of drinking water/groundwater contaminated with arsenic.

\section{ACKNOWLEDGEMENTS}

We acknowledge the administration of Sri K.G.S Arts College, Srivaikuntam, St. Xavier's College (Autonom ous), Palayamkottai and Rani Anna Government College for Women, Tirunelveli for all the laboratory studies.

\section{Conflict of interest}

The authors declare that they have no conflict of interest.

\section{REFERENCES}

1. Adamson, A.W. (1990). Physical Chemistry of Surfaces, (5th edition) John Wiley \& Sons Inc, Newyork, USA.

2. Agrawal, S. \& Singh, N.B. (2016). Removal of arsenic from aqueous solution by an adsorbent nickel ferritepolyaniline nanocomposite. Indian J. Chem. Technol., 23, 374-383.

3. Ansari, R., Feizy, J. \& Delavar, A.F. (2008). Removal of Arsenic ions from aqueous solutions using conducting polymers. E. J. Chem., 5(4), 853-863.

4. Bhaumik, M., Noubactep, C., Gupta, V.K., McCrindle, R.I. \& Maity, A. (2015). Polyaniline/Fe $\mathrm{F}^{\circ}$ composite nanofibers: An excellent adsorbent for the removal of arsenic from aqueous solution. Chem. Eng. J., 271, 135-146.

5. Boeva, Z.A., \& Sergeyev, V.G. (2014). Polyaniline: synthesis, properties, and application, Polym. Sci. Ser C., 56, 144-153.

6. Chang, Q., Lin, W. \& Ying, W.C. (2010). Preparation of iron-impregnated granular activated carbon for arsenic removal from drinking water. J. Hazard. Mater., 184(1-3), 515-522.

7. Davodi, B. \& Jahangiri, M. (2014). Determination of optimum conditions for removal of As (III) and As (V) by polyaniline/polystyrene nanocomposite. Synth. Met., 194, 97101.

8. Dutta, S., Manna, K., Srivastava, S.K., Gupta, A.K. \& Yadav, M.K. (2020). Hollow polyaniline microsphere/ $\mathrm{Fe}_{3} \mathrm{O}_{4}$ nanocomposite as an effective adsorbent for removal of arsenic from water. Sci Rep., https://doi.o $\mathrm{rg} / 10.1038 / \mathrm{s} 41598-020-61763-\mathrm{z}$

9. Fayazi, M., Ali, M. \& Afzali Detal. (2016). Synthesis and application of novel ion-imprinted polymer coated magnetic multi-walled carbon nanotubes for selective solid phase extraction of lead (II) ions. Mater. Sci. Eng C., 60, 365-373.

10. Ho, Y.S. \& McKay, G. (1999). Pseudo-Second Order Model for Sorption Processes. Proc. Biochem., 34, 451-465.

11. JansiRani, M., Murugan, M., Subramaniam, P. \& Subramanian, E. (2014). Adsorptive removal of arsenic from aqueous solution on PSLW carbon (Prosopis spicigera L. wood): Equilibrium, kinetics, thermodynamics and homewater treatment studies. Res. J. Chem. Environ., 18(2), 16.

12. Jeffery, G.H., Bassett, J., Mendham, J. \& Denny, R.C. (1989). Vogel's Textbook of Quantitative Chemical Analysis $\left(5^{\text {th }}\right.$ edition). Longmann Scientific \& Technical, England.

13. Jiang, Y., Liu, Z., Zeng, G., Liu, Y., Shao, B., Li, Z., Liu, 
Y., Zhang, W. \& He, Q. (2018). Polyaniline-based adsorbents for removal of hexavalent chromium from aqueous solution: a mini review. Environ Sci Pollut Res., 25, 61586174. https://doi.org/10.1007/s11356-0171188-3

14. Lagergren, S. (1898). Zurtheorie der sogenannten adsorption geloesterstoffe, Kungligasvenska Ventenskapsakademiens. Handlingar, 24, 1-39.

15. Lashkenari, M.S., Davodi, B. \& Eisazadeh, H. (2011). Removal of arsenic from aqueous solution using polyaniline/rice husk nanocomposite. Korean. J. Chem. Eng., 28, 1532-1538.

16. Li, J., Huang, Y. \& Shao, D. (2015). Conjugated polymerbased composites for water purification. In: Saini P (ed) Fundamentals of conjugated polymer blends, copolymers and composites: synthesis, properties, and applications. Scrivener, 581-620.

17. Mahmoud, M.E., Saad, E.A. \& El-Khatib, A.M. (2018) Green solid synthesis of polyaniline-silver oxide nanocomposite for the adsorptive removal of ionic divalent species of $\mathrm{Zn} / \mathrm{Co}$ and their radioactive isotopes $65 \mathrm{Zn} / 60 \mathrm{Co}$. Environ Sci Pollut Res., 25, 22120- 22135. https:// doi.org/1 0.1007/s11356-018-2284-8

18. Mckay, G., Balir, H.S. \& Garden, J.R. (1982). Adsorption of dyes on Chitin I equilibrium studies. J. Appl. Polym Sci., 27, 3043-3057.

19. Nodeh, M.K.M., Gabris, M.A., Nodeh, H.R. \& Bidhendi, M.E (2018). Efficient removal of arsenic(III) from aqueous media using magnetic polyaniline-doped strontium - titanium nanocomposite. Environ Sci Pollut Res., 25, 1686416874.https://doi.org/ 10.1007/s11356-018-1870-0

20. Mohan, D., Pittman, C.U. (2007). Arsenic removal from water/wastewater using adsorbents-a critical review. $J$ Hazard Mater., 142, 1-53.

21. Munoz, J.A., Gonzalo, A. \& Valiente, M. (2002). Arsenic adsorption by $\mathrm{Fe}$ (III)-loaded open-celled cellulose sponge. Thermodynamic and selectivity aspects. Environ. Sci. Technol., 36, 3405-3411.

22. Ogata, F., Kawasaki, N., Nakamura, T. \& Tanada, S. (2006). Removal of arsenious ion by calcined aluminium oxyhydroxide (boehmite). J. Colloid Interface Sci., 300, 88-93.

23. Palit, D. \& Moulik, S.P. (2000). Adsorption of methylene blue on cellulose from its own solution and its mixture with methyl orange. Indian J. Chem., 39 A, 611-617.

24. Podder, M.S. \& Majumder, C.B. (2016). Kinetic, mechanistic and thermodynamic studies of removal of arsenic using Bacillus arsenicus MTCC 4380 immobilized on surface of granular activated carbon/ $\mathrm{MnFe}_{2} \mathrm{O}_{4}$ composite. Groundw. Sustain. Dev., 2, 53-72.

25. Potgiefer, J.H. (1991). Adsorption of methylene blue on activated carbon: An experiment illustrating both the Langmuir and Freundlich isotherms. J. Chem. Edu., 68, 349.

26. Purwajanti, S. (2016). Mesoporous magnesium oxide hollow spheres as superior arsenite adsorbent: Synthesis and Adsorption Behavior. ACS Appl. Mater. Interfaces. 8, 25306-25312.

27. Reynolds, T.D. \& Richards, P.A. (1996). Unit operations and process in Environmental Engineering. PWS Boston, USA.

28. Roy, P., Mondal, N.K., Bhattacharya, S., Das, B. \& Das, K. (2013). Removal of arsenic(III) and $\operatorname{arsenic}(\mathrm{V})$ on chemically modified low-cost adsorbent: batch and column operations. Appl. Water Sci., 3, 293- 309.

29. Schwarz, J.A., Driscoll, C.T. \& Bharot, A.K. (1984). The zero point of charge of silica-alumina oxide suspensions. J. Colloid Interface Sci., 97, 55-61.

30. Semerjian, L. (2010). Equilibrium and kinetics of cadmium adsorption from aqueous solutions using untreated Pinushalepensis sawdust. J. Hazard. Mater., 173, 236-242.

31. Shabnam, R. (2017). Novel magnetically doped Epoxide functional cross-linked hydrophobic Poly(lauryl methacrylate) composite polymer particles for removal of As(III) from aqueous solution. Ind. Eng. Chem. Res., 56, 77477756 .

32. Thomas, H.C. (1948). Chromatography: a problem in kinetics. Ann. N.Y. Acad Sci., 49, 161-182.

33. Weber, T.W. \& Chakraborti, R.K. (1974). Pore and solid diffusion models for fixed-bed adsorbers. J. Am. Inst. Chem. Eng., 20, 228-238.

34. Yang, P.C., Du, J., Peng, Q., Qiao, R., Chen, W., Xu, C., Shuai, Z. \& Gao, M. (2009). Polyaniline/Fe3O4 nanoparticle composite: Synthesis and reaction mechanism. J. Phys. Chem. B, 113, 5052-5058.

35. Zhou, Q., Wang, J., Liao, X., Xiao, J. \& Fan, H. (2015). Removal of $\mathrm{As}(\mathrm{III})$ and $\mathrm{As}(\mathrm{V})$ from water using magnetic core-shell nanomaterial $\mathrm{Fe}_{3} \mathrm{O}_{4} @$ polyaniline. Int. J. Green Technol., 1, 54-64.

36. Zhu, H., Jia, Y., Wu, X. \& Wang, H. (2009). Removal of arsenic from water by supported nano zero-valent iron on activated carbon. J. Hazard. Mater., 172, 1591-1596. 